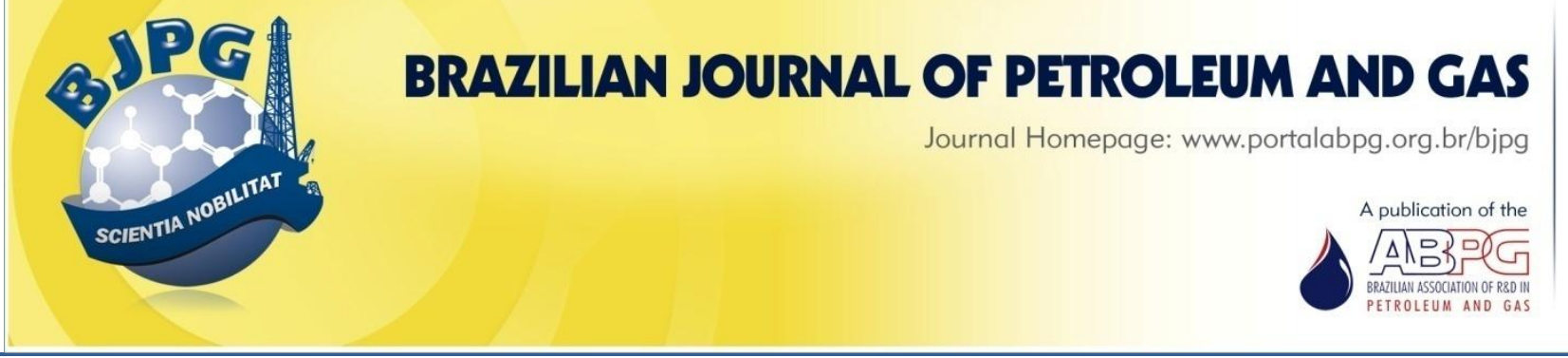

\title{
WELL DELIVERABILITY PREDICTIONS OF GAS FLOW IN GAS-CONDENSATE RESERVOIRS, MODELLING NEAR-CRITICAL WELLBORE PROBLEM OF TWO PHASE FLOW IN 1 -DIMENSION
}

\author{
${ }^{a}$ Orodu, O. D. ${ }^{1} ;{ }^{a}$ Ako, C. T.; ${ }^{a}$ Makinde, F. A.; ${ }^{\text {a }}$ Owarume, M. O. \\ ${ }^{\text {a }}$ Covenant University, Department of Petroleum Engineering, Ogun State, Nigeria
}

\begin{abstract}
Production of gases from gas-condensate reservoirs are known to bear certain challenges largely due to the formation of retrograde condensates that hinder gas flow. The drop out of this liquid creates flow regions that are characterized by the liquid saturation as it affects the mobility of the two phase flow, thereby preventing the effective modeling of well productivity. In this study, a predictive model based on an analytical approach is developed to predict gas flow in gas condensate reservoirs. This study compares the estimated gas flow from the developed model for gas-condensate reservoirs to the flow of an existing model for gas reservoirs. This study observes the effects of liquid drop-out on productivity at low pressures and the condensate unloading pressure, which is comparable to that of commercial software.
\end{abstract}

\section{KEYWORDS}

well deliverability modeling; wellbore problems; two- phase flow; 1-Dimension

\footnotetext{
${ }^{1}$ To whom all correspondence should be addressed.

Address: Department of Petroleum Engineering, School of Engineering, College of Science \& Technology, Covenant University, Km. 10 Idiroko Road, Ota, Ogun State, Nigeria

Telephone: +234 (0) 7061132990 | E-mail: david.orodu@covenantuniversity.edu.ng, preye.d.orodu@gmail.com doi:10.5419/bjpg2012-0013
} 


\section{INTRODUCTION}

Reservoirs bearing gas condensates are becoming more common as developments are encountering greater depths and higher pressures and temperatures. Accuracy in engineering computations for gas-condensate systems such as precision in well testing, in estimating reserves, in sizing surface facilities, and in predicting productivity trends depends upon basic understanding of phase and flow relationships. When comparing dry gas reservoirs with gascondensate reservoirs, one can observe the existence of many special factors that affect the performance of gas-condensate reservoirs during the exploitation process.

At the time of discovery, a typical gascondensate reservoir pressure might be above or close to the critical pressure. At this time, there exists only single-phase gas. However, as the production is carried out, decline in isothermal pressure occurs. Also, and as the bottom-hole pressure in a flowing well falls below the dew point of the fluid, a liquid-hydrocarbon phase is formed. The formation of a retrograde condensate results in a buildup of a liquid phase around the wellbore, leading to a decrease in the effective permeability to gas into the wellbore. The productivity loss associated with condensate buildup can be substantial. Afidick et al. (1994) and Barnum et al. (1995) listed several instances in which well productivities have been reported to decline by a factor of two to four as a result of condensate accumulation. Barnum et al. (1995) found that production loss is severe for low productivity reservoirs, such as those with a $K_{h}$ less than $1000 \mathrm{md}$-ft. They reported that the critical condensate saturation range from $10-30 \%$ and can decrease the productivity by a factor up to five due to condensate accumulation near the well bore.

Fevang (1995), Ali et al. (1997), and Gringarten and Al-Lamki (2000) showed that, when reservoir pressure around a well drops below the dew point pressure, retrograde condensation occurs and three regions are created with different liquid saturations.

Various models have been developed to study deliverability. Among these models is the steadystate flow concept by O'Dell and Miller (1965), with pessimistic production rates at average reservoir pressure below saturation pressure of fluid-in-place. Later, Fussell (1973) modified the version of 1-D radial model developed by Roebuck et al. (1969) to study long term well performance. Despite the modifications, the condensate accumulations in the producing region remained greater than the ones obtained experimentally for the constant volume depletion process. Cable et al. (2000) adopted the use of special core analysis data for near-well relative permeability to model productivity in a full-field model. Their study considers the importance of liquid recovery and change in yield, composition gradients, and reduction in well deliverability caused by condensate blockage.

Because the most important and complex phenomena associated with condensate banking and productivity reduction is relative permeability, there have been many investigations of gas condensate relative permeability. Hinchman and Barree (1985) showed that the productivity above the dew point pressure is controlled by the reservoir's permeability and thickness, in addition to the viscosity of the gas. Below the dew point, the degree of productivity reduction is controlled by the critical condensate saturation and the shape of the gas and condensate relative permeability curves, as well as the choice between imbibitions and drainage relative permeability curves. Whitson et al. (1999) showed that relative permeability effects in gas-condensate reservoirs can be classified into three categories: near well steadystate gas/oil flow; bulk of reservoir, beyond well vicinity, where liquid mobility is zero/ negligible; and water encroachment, where gas and/or retrograde condensate are trapped.

Bauget et al. (2005) developed a novel approach for calculating representative field relative permeability. This method is based on a physical model that takes into account the various mechanisms of the process: bubble nucleation (pre-existing bubbles model), phase transfer (volumetric transfer function), and gas displacement (bubble flow). In the model, the researchers identified a few invariant parameters which were not sensitive to depletion rate and were specific to the rock/fluid system. These invariant parameters were determined by history matching one experiment at a given depletion rate.

Jamiolahmady et al. (2006) used a large data 
bank of gas/condensate relative permeability to develop a general correlation accounting for the combined effect of coupling and inertia as a function of fractional flow. The parameters of the new correlation were either universal, applicable to all types of rocks, or could be determined from commonly measured petrophysical data. And, Bozorgzadeh and Gringarten (2007) showed that well deliverability depends mainly on the gas relative permeabilities at both the end point and near wellbore saturation, as well as on the reservoir permeability.

This work studies well deliverability (productivity) predictions of gas flow in a gascondensate reservoir modeling near critical wellbore problems in 1-D. Since gas condensate is a mixture of gas and liquid, this work will focus on finding the optimum way to improve gas flow (reducing condensate build up) around the well bore.

\section{METHODOLOGY}

The typical chemical composition of a gascondensate mixture is dominated by volatile components such as methane, and a rather 'small' amount of heavy hydrocarbon components (<15mol-\%). Despite its composition, these heavier components make up a considerably larger percentage of the liquid phase, retrograde condensate, formed during pressure decrease below an upper dew point (McCain Jr., 1989). This study is based on a fluid characterized by $\mathrm{C} 7+$ of $13.35 \mathrm{~mol}-\%$ and molecular weight of $144.77 \mathrm{~g} / \mathrm{mol}$.; GOR, $3414.6 \mathrm{scf} / \mathrm{sepp} \mathrm{bbl} ; 51.2^{\circ} \mathrm{API}$, and reservoir fluid molecular weight of $40.22 \mathrm{~g} / \mathrm{mol}$.

For practically any retrograde condensate reservoir, the condensate saturation is, throughout most of the reservoir, so low that its mobility is much less than gas mobility. For practical purposes it can be considered immobile. Nevertheless, this gas-dominated flow behavior is not at all correct in the vicinity of gas-condensate wells, where condensate saturations often reach high values $(>50 \%)$, and oil permeability may exceed gas permeability $(\mathrm{krg} / \mathrm{kro}<1)$.

Condensate blockage near the wellbore may reduce gas well deliverability appreciably, though the severity of the obstruction depends on a number of reservoir and well parameters. Condensate blockage is deemed important if the pressure drop from the reservoir to the wellbore represents a significant percentage of the total pressure drop from reservoir to delivery point (e.g. a surface separator) at the time and after a well goes on decline. Reservoirs with low-to-moderate permeability $(<10-50 \mathrm{md})$ are often considered problem wells and it becomes critical to address the condensate blockage issue properly. Wells with high $k_{\mathrm{h}}$ products $(>5-10,000 \mathrm{md}-\mathrm{ft}$ ) are typically not affected by reservoir pressure drop because the well's deliverability is constrained almost entirely by the tubing. In this case, condensate blockage is a non-issue. In terms of reservoir well performance, the near-well behavior, determined by the nearwell relative permeability functions, is the dominant factor.

The diffusivity equation (Eq. 1) is solved based on dimensionless groups with respect to certain conditions and assumptions which are elaborated and stated below.

$$
\frac{1}{r} \frac{\partial}{\partial r}\left(r \frac{\partial p}{\partial r}\right)=\frac{\varphi \mu C_{t}}{k} \frac{\partial p}{\partial t}
$$

An expression for total compressibility (Eq. 2) with respect to the pressure derivative of oil formation volume factor and oil saturation was proposed. It was derived based on the combination continuity equation for the rate of in and out a control volume made up of a porous medium for oil and gas respectively (see Appendix). This is incorporated into the diffusivity equation.

$$
\left(S_{o}^{\prime}-\frac{S_{o} B_{o}^{\prime}}{B_{o}}\right)\left(\frac{\lambda_{t}}{\lambda_{o}}\right)=C_{t}
$$

where

$$
B_{o}^{\prime}=\frac{\partial}{\partial p}\left(\frac{1}{B_{o}}\right) \quad \text { and } \quad S_{o}^{\prime}=\frac{\partial S_{o}}{\partial p}
$$

Where $r$ represents the radius; $p$, pressure; $\varphi$, porosity; $\mu$, viscosity; $k$, permeability; $C_{t}$, total compressibility; $t$, time; $S_{o}$, oil saturation; $B_{0}$, oil formation volume factor; $\lambda_{t}$, total mobility, and $\lambda_{0}$, oil mobility.

The reservoir is categorized pseudo-steady in nature having a constant production. The wellbore 
is classified as finite. The flow in the reservoir is also considered with a no-flow outer boundary. Physically, a no-flow outer boundary could be sealing faults or pinch-outs. For the mathematical interpretation of these conditions, certain mathematical relations such as Laplace and Bessel functions are put in use. Also, to make the simplification easier, dimensionless groups are used. From the diffusivity equation, the partial differential equation is given by:

$\frac{1}{r_{D}} \frac{\partial}{\partial r_{D}}\left(r_{D} \frac{\partial p_{D}}{\partial r_{D}}\right)=\frac{\partial p_{D}}{\partial t_{D}}$

where $r_{D}, p_{D}$ and $t_{D}$ are dimensionless radius, dimensionless pressure and dimensionless time, respectively.

At initial conditions,

$p_{D}\left(r_{D}, t_{D}=0\right)=0$

The inner boundary condition is constant rate production,

$\left(r_{D} \frac{\partial p_{D}}{\partial r_{D}}\right)_{\left(r_{D}=1\right)}=-1$

The outer boundary condition is for a no-flow boundary,

$\left(\frac{\partial p_{D}}{\partial r_{D}}\right)_{r_{e D}}=0$

Taking the Laplace transform of the partial differential equation, Eq. 3;

$\mathcal{L}\left\{\frac{1}{r_{D}} \frac{\partial}{\partial r_{D}}\left(\frac{\partial p_{D}}{\partial r_{D}}\right)\right\}=\mathcal{L}\left(\frac{\partial p_{D}}{\partial t_{D}}\right)$

This converts the partial differential equation into ordinary differential equations,

$\frac{1}{r_{D}} \frac{d}{d r_{D}}\left(r_{D} \frac{d p_{D}}{d r_{D}}\right)=U P_{D}-P_{D}\left(r_{D}, t_{D}=0\right)$

Where;

$\mathcal{L}\left(\frac{\partial p}{\partial t}\right)=U P_{D}-P(t=0)$

(9) $\quad\left(r_{D} \frac{d p_{D}}{d r_{D}}\right)_{\left(r_{D}=1\right)}=-\frac{1}{U}$
Substituting the initial conditions, Eq. 4 into Eq. 8:

$\frac{1}{r_{D}} \frac{d}{d r_{D}}\left(r_{D} \frac{d p_{D}}{d r_{D}}\right)=U P_{D}$

Where Eq. 10 has the form of the modified Bessel equation,

$\frac{1}{x} \frac{d}{d x}\left(x \frac{d v}{d x}\right)-\lambda v=0$

This represents the general solution for:

$V=A I_{o}(\sqrt{\lambda} x)+B K_{o}(\sqrt{\lambda} x)$

Therefore, the general solution of Eq. 10 gives:

$P_{D}=A I_{o}\left(\sqrt{U} r_{D}\right)+B K_{o}\left(\sqrt{U} r_{D}\right)$

Where " $A$ " and " $B$ " are arbitrary constants determined by the boundary conditions.

Taking the Laplace transform of the boundary condition, Eq. 6 gives:

$\left(\frac{d P_{D}}{d r_{D}}\right)_{\left(r_{c D}\right)}=0$

Differentiating Eq. 13, one can obtain:

$\left(\frac{d P_{D}}{d r_{D}}\right)=A \sqrt{U} I_{1}\left(\sqrt{U} r_{D}\right)+B \sqrt{U} K_{1}\left(\sqrt{U} r_{D}\right)$

At $r_{D}=r_{e D}$, this gives,

$0=A \sqrt{U} I_{1}\left(\sqrt{U} r_{e D}\right)+B \sqrt{U} K_{1}\left(\sqrt{U} r_{e D}\right)$

Writing " $A$ " in Eq. 16 in terms of " $B$ ", gives:

$A=\frac{B \sqrt{U} K_{1}\left(\sqrt{U} r_{e D}\right)}{A \sqrt{U} I_{1}\left(\sqrt{U} r_{e D}\right)}=\frac{K_{1}\left(\sqrt{U} r_{e D}\right)}{I_{1}\left(\sqrt{U} r_{e D}\right)} B$

Using the other conditions to solve for the constants " $A$ " and " $B$ ".

The inner boundary in Laplace space is:

Substituting Eq. 18 into Eq. 15: 
$-\frac{1}{U}=A \sqrt{U} I_{1}\left(\sqrt{U} r_{e D}\right)-B \sqrt{U} K_{1}\left(\sqrt{U} r_{e D}\right)$

Substituting Eq. 17 into Eq. 19 and solving for $B$,

$$
B=-\frac{1}{U^{3 / 2}}\left[\frac{I_{1}\left(\sqrt{U} r_{e D}\right)}{K_{1}\left(\sqrt{U} r_{e D}\right) I_{1}(\sqrt{U})-I_{1}\left(\sqrt{U} r_{e D}\right) K_{1}(\sqrt{U})}\right]
$$

One can now solve for " $A$ ", by substituting the relationship for the constant " $B$ " given in Eq. 20 into Eq. 17:

$$
A=-\frac{1}{U^{3 / 2}}\left[\frac{K_{1}\left(\sqrt{U} r_{e D}\right)}{K_{1}\left(\sqrt{U} r_{e D}\right) I_{1}(\sqrt{U})-I_{1}\left(\sqrt{U} r_{e D}\right) K_{1}(\sqrt{U})}\right]
$$

Substituting Eq. 21 and Eq. 20 into Eq. 13:

$$
P_{D}=-\frac{1}{U^{3 / 2}}\left[\frac{K_{1}\left(\sqrt{U} r_{e D}\right) I_{o}\left(\sqrt{U} r_{D}\right)+I_{1}\left(\sqrt{U} r_{e D}\right) K_{o}\left(\sqrt{U} r_{D}\right)}{K_{1}\left(\sqrt{U} r_{e D}\right) I_{1}(\sqrt{U})-I_{1}\left(\sqrt{U} r_{e D}\right) K_{1}(\sqrt{U})}\right]
$$

This is the dimensionless pressure solution in terms of $U$ and $r_{D}$. Using the Cauchey's inversion theorem (O'Neil, 1987), the solution becomes:

$$
\begin{aligned}
& P_{D}\left(r_{D}, t_{D}\right)=\frac{2}{\left(r_{e D}^{2}-1\right)}\left(\frac{r_{D}^{2}}{4}+t_{D}\right)- \\
& -\frac{r_{e D}^{2} \ln r_{D}}{\left(r_{e D}^{2}-1\right)}-\frac{\left(3 r_{e D}^{4}-4 r_{e D}^{4} \ln r_{e D}-2 r_{e D}^{2}-1\right)}{4\left(r_{e D}^{2}-1\right)^{2}}
\end{aligned}
$$

For the pressure at wellbore, $P_{w D}, r_{e D}>>1$, Eq. 23 becomes:

$$
\begin{aligned}
& P_{w D}\left(t_{D}\right)=\frac{2}{\left(r_{e D}^{2}\right)}\left(\frac{1}{4}+t_{D}\right)-\frac{r_{e D}^{2} \ln 1}{\left(r_{e D}^{2}\right)}-\frac{3 r_{e D}^{4}}{4 r_{e D}^{4}}- \\
& -\frac{4 r_{e D}^{4} \ln r_{e D}}{4 r_{e D}^{4}}-\frac{1}{2 r_{e D}^{2}}-\frac{1}{4 r_{e D}^{4}}=\frac{2 t_{D}}{\left(r_{e D}^{2}\right)}-\frac{3}{4}+\ln r_{e D}
\end{aligned}
$$

In order to convert to field units, the dimensionless groups have to be properly expressed.

$$
t_{D}=\frac{0.0002637 t}{\varphi r_{w}^{2}} \times \frac{k}{\mu} \times \frac{1}{C_{t}}
$$

Since this experiment considers two phases (gas and oil): $\frac{k}{\mu}=\frac{k_{o}}{\mu_{o}}+\frac{k_{g}}{\mu_{g}} \quad ; \quad \frac{1}{C_{t}}=\frac{1}{S_{o} C_{o}+S_{g} C_{g}+C_{f}}$

Therefore,

$t_{D}=\frac{0.0002637 t}{\varphi r_{w}^{2}}\left(\frac{k_{g}}{\mu_{g}}+\frac{k_{g}}{\mu_{g}}\right)\left(\frac{1}{S_{o} C_{o}+S_{g} C_{g}+C_{f}}\right)$

$r_{e D}=\frac{r_{e}}{r_{w}}$

Where $r_{w}$ is well radius; $r_{e}$, reservoir radius; $k_{o}$, relative permeability to oil; $k_{g}$, relative permeability to gas; $\mu_{o}$, oil viscosity; $\mu_{g}$, gas viscosity; $S_{0}$, oil saturation; $S_{g}$, gas saturation; $C_{f}$, formation compressibility; $C_{o}$, oil compressibility; $C_{g}$, gas compressibility and others are as defined for Equations 1 to 2 .

$p_{w D}=\frac{h}{141.2 q B}\left(p_{i}-p_{w f}\right)\left(\frac{k_{o}}{\mu_{o}}+\frac{k_{g}}{\mu_{g}}\right)$

Substituting Eq.29, 28 and 25 into Eq. 24:

$$
p_{w f}=p_{i}-\frac{141.2 q B}{\left(\frac{k_{o}}{\mu_{o}}+\frac{k_{g}}{\mu_{g}}\right) h} \times\left[\frac{0.0002637 t}{\varphi r_{e}^{2}}\left(\frac{k_{o}}{\mu_{o}}+\frac{k_{g}}{\mu_{g}}\right) x\right.
$$

$\left.x\left(\frac{1}{S_{o} C_{o}+S_{g} C_{g}+C_{f}}\right)-\frac{3}{4}+\ln \left(\frac{r_{e}}{r_{w}}\right)\right]$

Where $p_{w f}$ is bottom hole flowing pressure; $p_{i}$ initial reservoir pressure; $q$, flow rate; $h$, reservoir height, and others are as previously defined.

This equation (Eq. 30) shall be used to predict gas production performance in comparison with existing solution.

\section{RESULTS AND DISCUSSION}

The objective of this study is built around the accurate prediction of the deliverability of gas in a gas condensate reservoir. It takes into consideration the various limiting factors to the proper production from such reservoirs. In this context, condensate blockage represents the main problem experienced in these reservoirs, and is generally known to alter the deliverability as a 
Table 1. Reservoir and well parameters.

\begin{tabular}{ll}
\hline Reservoir Pressure & 4903 psia \\
Reservoir Temperature & $200^{\circ} \mathrm{F}$ \\
Porosity & 0.20 \\
Saturation Pressure & $4440 \mathrm{psia}$ \\
Reservoir Radius & $800 \mathrm{ft}$ \\
Reservoir Wellbore Radius & $0.369 \mathrm{ft}$ \\
Reservoir Depth & $10000 \mathrm{ft}$ \\
Depth of Mid Perforations & $8000 \mathrm{ft}$ \\
Well head Pressure & $1000 \mathrm{psia}$ \\
Well head Temperature & $40^{\circ} \mathrm{F}$ \\
\hline
\end{tabular}

Table 2. Reservoir fluid PVT data.

\begin{tabular}{ccccccccc}
\hline $\begin{array}{c}\text { Pressure } \\
\text { psia }\end{array}$ & $\begin{array}{c}\text { Gas Density } \\
\mathrm{g} / \mathrm{cm}^{3}\end{array}$ & z-Factor & $\begin{array}{c}\text { Gas FVF } \\
\mathrm{cu} \mathrm{ft/SCF}\end{array}$ & $\begin{array}{c}\text { Relative } \\
\text { Vol. }\end{array}$ & $\begin{array}{c}\text { Gas Viscosity } \\
\mathrm{cp}\end{array}$ & $\begin{array}{c}\text { Gas Compr. } \\
\mathrm{psia}^{-1}\end{array}$ & $\begin{array}{c}\text { Gas } \\
\text { Saturation }\end{array}$ & $\begin{array}{c}\text { Oil } \\
\text { Saturation }\end{array}$ \\
\hline 4440 & 0.429 & 0.818 & 0.00344 & 1.000 & - & - & 1.00000 & 0.00000 \\
4415 & 0.249 & 0.890 & 0.00375 & 1.002 & 0.0298 & $3.54 \mathrm{E}-05$ & 0.80000 & 0.20000 \\
4295 & 0.243 & 0.882 & 0.00382 & 1.012 & 0.0291 & $4.13 \mathrm{E}-05$ & 0.74375 & 0.25625 \\
3858 & 0.222 & 0.860 & 0.00415 & 1.066 & 0.0265 & $5.13 \mathrm{E}-05$ & 0.68750 & 0.31250 \\
3453 & 0.200 & 0.846 & 0.00456 & 1.141 & 0.0243 & $6.11 \mathrm{E}-05$ & 0.63125 & 0.36875 \\
3048 & 0.175 & 0.841 & 0.00514 & 1.241 & 0.022 & $6.49 \mathrm{E}-05$ & 0.57500 & 0.42500 \\
2241 & 0.126 & 0.848 & 0.00705 & 1.503 & 0.0183 & $7.92 \mathrm{E}-05$ & 0.51875 & 0.48125 \\
1433 & 0.076 & 0.883 & 0.00721 & 2.752 & 0.0155 & $8.02 \mathrm{E}-05$ & 0.46250 & 0.53750 \\
1044 & 0.055 & 0.907 & 0.00750 & 3.271 & 0.0146 & $8.76 \mathrm{E}-05$ & 0.40625 & 0.59375 \\
\hline
\end{tabular}

result of reduced permeability. The method employed involves an analytical approach. It may not prove to be as detailed or as thorough as the method of numerical approximations which, however, is more complex in nature.

The approach used to validate this research is as follows: obtaining accurate field data (preferably a variety of them), using the obtained data to make computations with the developing correlations, using the obtained data to make computations with established correlations either similar or closely related in nature, making comparisons with obtained results, and making suitable arguments to back them up.

The field data used is shown in Table 1. Table 2 is obtained from a PVT analysis, these data have aided the analysis of this work.

\subsection{Computation - Darcyan and Non- Darcyan (Models)}

Using the derived/developed correlation below for a simplified 2-phase Non-Darcy unsteady state (from Eq. 30), computations where made to obtain the flow rate of the gas phase, as seen in Table 3.

Likewise, the established correlation for Darcy steady state flow of natural gas is used to predict produced gas.

$p_{e}^{2}-p_{w f}^{2}=\frac{1424 q \mu Z T}{k h}\left(\ln \frac{r_{e}}{r_{w}}+s\right)$

Darcy's relationship for steady state flow of gas (Eq. 31) is used to predict this result. Darcy's model cannot be looked at as an exact comparison to the developed correlation for the 2-phase unsteady state used in this study. However, considering the 
Table 3. Predicted gas flow rate.

\begin{tabular}{cccc}
\hline $\begin{array}{c}\text { P (initial) } \\
\text { psia }\end{array}$ & $\begin{array}{c}\mathbf{P}_{\text {wf }} \\
\text { psia }\end{array}$ & $\begin{array}{c}\text { Non-Darcyan } \\
\text { q(MSCF/D) }\end{array}$ & $\begin{array}{c}\text { Darcyan } \\
\text { q(MSCF/D) }\end{array}$ \\
\hline 4440 & 4440 & 0 & 0 \\
4440 & 4415 & 68.115 & 51.084 \\
4440 & 4295 & 387.826 & 649.207 \\
4440 & 3858 & 1432.871 & 1196.944 \\
4440 & 3453 & 2211.488 & 1756.095 \\
4440 & 3048 & 2766.994 & 2375.172 \\
4440 & 2241 & 3186.897 & 3651.326 \\
4440 & 1433 & 4261.179 & 4786.304 \\
4440 & 1044 & 4626.343 & 5163.696 \\
\hline
\end{tabular}

deliverability of gas, this relationship can be used with the allowance of certain discrepancies.

The application of Eq. 30 utilizes PVT data (Table 2) and special core analysis data to carry out the following comparisons. Corey's relationship permeability model is used to fit measured core data, $k_{d} / k_{g}$ ratio is obtained from $k g / k o=\left(1 / V_{\text {roCCE }}-1\right)\left(\mu_{g} / \mu_{o}\right)$ where $\mu_{g}$ and $V_{\text {roCCE }}$ are extracted from PVT data and $V_{\text {rocCE }}$ is a constant composition expansion oil relative volume. The outer reservoir radius is at the point where condensate saturation is above critical condensate saturation. The pressure at this point is the dew point pressure; this is actually the near wellbore region, as explained in the next sub section. All other parameters required to compute flow rate in Eqn. 30 are as listed in Tables 1 and 2.

\subsection{Comparison of correlation (models)}

Comparison of the two IPR results can be observed in Figure 1. The entire study is centered on Regions 1 and 2. Region 1 is characterized by condensate saturation above critical condensate saturation (CCS) and, hence, both gas and liquid phases are mobile. Region 1 is the main source of deliverability loss in a gas-condensate well. Gas relative permeability is reduced drastically in this region due to condensate buildup. The reduction in relative permeability to gas reaches its highest levels in this region. Even though condensate buildup starts from region 2, the liquid phase is immobile. The two-phase flow in region 1 is the main cause of gas relative permeability reduction. Region 2 is the intermediate zone where condensate dropout begins and defines a region of net accumulation of condensate. The condensate saturation is below the critical value (Scc) and effectively only gas is flowing in this region because oil mobility is reduced or zero.

One can assume that the results obtained from the Darcy correlation are applicable to gas reservoirs that have very similar conditions to that

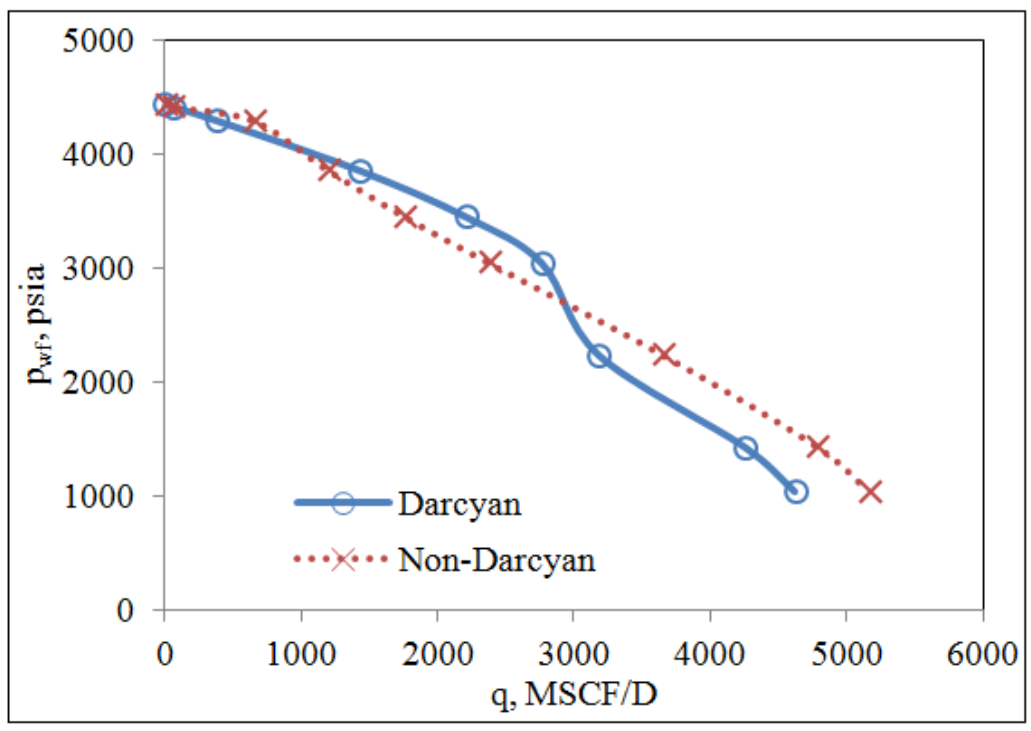

Figure 1. IPR of the developed correlation for Non-Darcyan and Darcyan models. 
of the condensate reservoir. During the early phase of production from region 2 , one can observe that the flow rate shown by the model developed in the present study is higher than the one shown by Darcy's correlation (Figure 1). This can be attributed to the fact that at this stage, the gas phase still has considerable mobility and the flow rate is still higher than that of the liquid phase. The difference in flow rate takes place because condensates are still building up. But, as the production pressure declines, the more the condensates build and leading to a reduction in the gas mobility. This leads to a situation where the flow rate of the gas shown under the developed correlation is lower than the flow rate shown by the Darcy correlation. That configures the phenomenon observed around region 1. The pressure point where the flow rate of gas starts to reduce represents the condensate unloading pressure. The condensate unloading pressure for the above scenario is about 2,250 psi.

The present study may contain shortcomings. Among the possible inaccuracies, the major points to consider are:

- The developed correlation is modeled with the assumption that the fluid flow is Darcy in nature, where as in the actual sense, it is a nonDarcy flow;

- An analytical approach was considered in the development of this correlation. This cannot be said to be a very detailed analysis because this approach deals with many assumptions and does not vary sufficient parameters;

- This method does not support a case scenario where the composition of the mixture is constantly changing with time. This can be seen, for example, when gas injection is carried out;

- The model strictly considers a two-phase flow (excluding water), which is observed in very rare cases. A better model would include water effects.

\section{CONCLUSIONS}

This study aimed to developing a method suitable for analyzing the delivery patterns of gas in a gas-condensate field using an empirical approach. It provides a simple deduction on a possible solution to a gas condensate challenge.
From the results obtained, it is safe to say that production must be carried out at a high flowing pressure (far above the dew point), irrespective of the corresponding flow rate. This is to prevent or prolong the formation of condensates that would further hinder production.

\section{NOMENCLATURE}

$\mu=$ viscosity

$\mu_{g}=$ gas viscosity

$\mu_{o}=$ oil viscosity

$B_{o}=$ oil formation volume factor

$C C S=$ critical condensate saturation

$C_{f}=$ formation compressibility

$C_{g}=$ gas compressibility

$C_{o}=$ oil compressibility

$C_{t}=$ total compressibility

$h=$ reservoir height

$k=$ absolute permeability

$k_{g}=$ relative permeability to gas

$k_{o}=$ relative permeability to oil

$p=$ pressure

$p_{D}=$ dimensionless pressure

$p_{i}=$ initial reservoir pressure

$p_{w D}=$ dimensionless pressure at wellbore

$p_{w f}=$ bottom hole flowing pressure

$q=$ flow rate

$r=$ radius

$r_{D}=$ dimensionless radius

$r_{e}=$ reservoir radius

$r_{w}=$ well radius

$S_{g}=$ gas saturation

$S_{o}=$ oil saturation

$t=$ time

$V_{\text {rocCE }}=$ constant composition expansion oil relative volume

$t_{D}=$ dimensionless time

$\lambda_{o}=$ oil mobility

$\lambda_{t}=$ total mobility

$\varphi=$ porosity

\section{REFERENCES}

Afidick, D. ; Kaczorowski, N. J.; Srivinas, B. Production performance of a retrograde gas reservoir: A case study of the Arun field. SPE paper 28749-MS, 1994. http://dx.doi.org/10.2118/28749-MS 
Ali, J. K.; Mc Gauley, P. J.;Wilson, C. J. Experimental studies and modeling of gas condensate flow near the wellbore. SPE paper 39053-MS, 1997. http://dx.doi.org/10.2118/39053-MS

Barnum, R. S.; Brinkman, F. P.; Richardson, T. W.; Spillette, A. G. Gas condensate reservoir behavior: Productivity and recovery reduction due to condensation. SPE paper 30767-MS, 1995. http://dx.doi.org/10.2118/30767-MS

Bauget, F.; Egermann, P.; Lenormand, R. A new model to obtain representative field relative permeability for reservoirs produced under solution-gas drive. SPE Journal of Reservoir Evaluation and Engineering, v.8(4), p. 348-356, 2005. http://dx.doi.org/10.2118/84543-PA

Bozorgzadeh, M.; Gringarten, A.C. Estimating productivity controlling parameters in gas/condensate wells from transient pressure data", SPE Reservoir Evaluation \& Engineering, v.10, p. 100-111, 2007.

http://dx.doi.org/10.2118/94018-PA

Cable A. S.; Mott R. E.; Mike S. X-Ray in-situ saturation in gas condensate relative permeability studies. SCA 2000 - 39 AEA Technology PLC, Winfrith Technology Center, Dorchester, Dorset, DT2 8ZE, UK, 2000.

Fevang, O.; Whitson, C. H.; Trondheim, U. Modeling gas condensate deliverability. SPE paper 30714-PA, SPE Reservoir Engineering, v. 11(4), p. 116, 1995.

Fussell, D. D. Single-well performance for gas condensate reservoirs. Journal of Petroleum Technology, v. 25(7), p. 860-870, 1973. http://dx.doi.org/10.2118/4072-PA

Gringarten, A. C.; Al-Lamki, A.; Daungkaew, S.; Mott, R.; Whittle, T. M. Well test Analysis in gas Ccondensate reservoirs. SPE paper 62920, 2000.

Hinchman, S. B.; Barree, R. D. Productivity loss in gas condensate reservoirs. SPE paper 14203-MS, 1985. http://dx.doi.org/10.2118/14203-MS

Jamiolahmady, M; Danesh, A.; Tehrani, D. H.; Sohrabi, M. Variations of gas/condensate relative permeability and production rate at near-wellbore conditions: A general correlation. SPE Journal of Reservoir Evaluation and Engineering, v. 9(6), p. 688-697, 2006. http://dx.doi.org/10.2118/83960-PA
Mc Cain Jr, W. D. The Properties of Petroleum Fluids, $2^{\text {nd }}$ Ed., PennWell Publishing Company, $p$. 155, 1989.

O'Dell, H. G.; Miller, R. N. Successfully cycling a low-permeability, high-yield gas condensate reservoir. SPE paper 1495-PA, p.41-47, 1967. http://dx.doi.org/10.2118/1495-PA

O'Neil, P.V. Advanced Engineering Mathematics. $2^{\text {nd }}$ Ed., Wadworth Publishing Co., Belmont, California, 1987.

Roebuck Jr., I. F.; Ford, W. T.; Henderson, G. E.; Douglas Jr., J. The compositional reservoir simulator: case iii - The radial geometry. Unpublished paper, available from Core Laboratories, Inc., Dallas, Texas, 1969.

Whitson, C. H.; Fevang, O.; Saevareid, A. Gas Condensate Relative Permeability for Well Calculations. SPE paper 56476, 1999.

\section{APPENDIX}

In determining the gas deliverability in a gas condensate reservoir, some equations have to be derived, taking into consideration fundamental principles of oil and gas flow. This is a more complex approach, considering that it involves two phases which do not present a constant compositional volume throughout the reservoir.

Starting from the basic diffusivity equation, which considers the principle of conservation of mass, an equation of motion, and an equation of state, one can attain the diffusivity equation. For a single-phase flow, the diffusivity equation is given by:

$$
\frac{1}{r} \frac{\partial}{\partial r}\left(r \frac{\partial p}{\partial r}\right)=\frac{\varphi \mu C_{t}}{k} \frac{\partial p}{\partial t}
$$

For the multiphase flow, one must consider the continuity equation for each phase. The equation includes a unit control volume containing oil and gas saturations $S_{o \text { and }} S_{g}$.

The oil mass balance of a system is represented by: 
$-\nabla \bar{M}_{o}=\frac{\partial m_{o}}{\partial t}$

Radial flow coordinates leads to:

$-\frac{1}{r} \frac{\partial \bar{M}_{o}}{\partial r} r=\frac{\partial m_{o}}{\partial t} \quad ; \quad \bar{M}_{o}=\rho_{o} u_{o} \quad ; \quad m_{o}=\rho_{o} \varphi s_{o}$

For oil flow in a radial system,

$-\frac{1}{r} \frac{\partial \rho_{o} u_{o}}{\partial r} r=\rho_{o s} \varphi \frac{\partial}{\partial t} \frac{S_{o}}{B_{o}}$

$u_{o}=-\frac{k_{o}}{\mu_{o}} \frac{\partial P}{\partial r} \quad ; \quad u_{o} \rho_{o}=-\rho_{o} \frac{k_{o}}{\mu_{o}} \frac{\partial P}{\partial r}=-\frac{\rho_{o s}}{B_{o}} \frac{k_{o}}{\mu_{o}} \frac{\partial P}{\partial r}$

Based on the on Darcy's equation of motion in a control volume for the oil phase,

$-\frac{1}{r} \frac{\partial}{\partial r}\left(\frac{1}{B_{o}}\right)\left(\frac{k_{o}}{\mu_{o}}\right) r \frac{\partial P}{\partial r}=\varphi \frac{\partial}{\partial t} \frac{S_{o}}{B_{o}}$

The equation above is simplified by assuming constant oil permeability, viscosity and formation volume factor.

$\frac{1}{r} \frac{\partial}{\partial r} r \frac{\partial P}{\partial r}=\varphi\left(\frac{B_{o} \mu_{o}}{k_{o}}\right) \frac{\partial}{\partial t} \frac{S_{o}}{B_{o}}$

Where $m_{o}$ is mass of oil per volume; $m_{g}$, mass of gas per unit volume and $\rho_{g s}$, represents gas density at standard condition; $\bar{M}_{o}$, mass flux; $\rho_{g}$, gas density; $\rho_{o s}$, oil density at standard condition; $\rho_{g}$, oil density; $u$, flow velocity; $\mu_{o}$, oil viscosity; $\mu_{g}$, gas viscosity; $k_{o}$, oil permeability; $k_{q}$, gas permeability; $B_{o}$, oil formation volume factor; $B_{g}$, oil formation volume factor; $S_{0}$, oil saturation; $S_{g}$, gas saturation; $\varphi$, porosity; $p$, pressure; $r$, radius, and $t$, time.

The continuity equation can be written for each phase considering that the rate of mass of the control volume less the rate of mass out is given by the following similarity of gas equation:

$\frac{1}{r} \frac{\partial}{\partial r}\left(r \frac{\partial p}{\partial r}\right)=\varphi \frac{\mu_{g} B_{g}}{k_{g}} \frac{\partial}{\partial t}\left(\frac{S_{g}}{B_{g}}\right)$

Expanding the partial derivatives, with respect to time, using chain rule and observing that the formation volume factors and solubility are functions of pressure:

$$
\begin{aligned}
& \frac{1}{r} \frac{\partial}{\partial r}\left(r \frac{\partial p}{\partial r}\right)=\varphi \frac{\mu_{o} B_{o}}{k_{o}} \frac{\partial}{\partial p}\left(\frac{S_{o}}{B_{o}}\right) \frac{\partial p}{\partial t}= \\
& =\varphi \frac{\mu_{o} B_{o}}{k_{o}}\left\{\frac{1}{B_{o}} \frac{\partial S_{o}}{\partial p} \frac{\partial p}{\partial t}+S_{o} \frac{\partial}{\partial p}\left(\frac{1}{B_{o}}\right) \frac{\partial p}{\partial t}\right\}
\end{aligned}
$$

Let,

$$
B_{o}^{\prime}=\frac{\partial}{\partial p}\left(\frac{1}{B_{o}}\right)
$$

$S_{o}^{\prime}=\frac{\partial S_{o}}{\partial p}$

$\frac{\partial}{\partial p}\left(\frac{1}{B_{o}}\right)=\frac{\partial}{\partial t}\left(B_{o}^{-1}\right)=-\frac{1}{B_{o}^{2}} \frac{\partial B_{o}}{\partial p}$

Therefore,

$\frac{1}{r} \frac{\partial}{\partial r}\left(r \frac{\partial p}{\partial r}\right)=\varphi \frac{\mu_{o} B_{o}}{k_{o}}\left(\frac{S_{o}^{\prime}}{B_{o}}-\frac{S_{o} B_{o}^{\prime}}{B_{o}^{2}}\right) \frac{\partial p}{\partial t}$

$\frac{1}{r} \frac{\partial}{\partial r}\left(r \frac{\partial p}{\partial r}\right)=\varphi \frac{\mu_{o}}{k_{o}}\left(S_{o}^{\prime}-\frac{S_{o} B_{o}^{\prime}}{B_{o}}\right) \frac{\partial p}{\partial t}$

Expanding Eq. A8:

$\frac{1}{r} \frac{\partial}{\partial r}\left(r \frac{\partial p}{\partial r}\right)=\varphi \frac{\mu_{g} B_{g}}{k_{g}} \frac{\partial}{\partial p}\left(\frac{S_{g}}{B_{g}}\right) \frac{\partial p}{\partial t}$

$\frac{1}{r} \frac{\partial}{\partial r}\left(r \frac{\partial p}{\partial r}\right)=\varphi \frac{\mu_{g} B_{g}}{k_{g}}\left(\frac{S_{g}^{\prime}}{B_{g}}-\frac{S_{g} B_{g}^{\prime}}{B_{g}^{2}}\right) \frac{\partial p}{\partial t}$

Oil and gas mobility are given by,

$$
\begin{gathered}
\lambda_{o}=\frac{k_{o}}{\mu_{o}} \\
\lambda_{g}=\frac{k_{g}}{\mu_{g}}
\end{gathered}
$$

Substituting Eq. A13 and A14 into $\mathrm{A} 11$ and $\mathrm{A} 12$ : 
$\frac{1}{r} \frac{\partial}{\partial r}\left(r \frac{\partial p}{\partial r}\right)=\varphi \frac{1}{\lambda_{o}}\left(S_{o}^{\prime}-\frac{S_{o} B_{o}^{\prime}}{B_{o}}\right) \frac{\partial p}{\partial t}$

$\frac{1}{r} \frac{\partial}{\partial r}\left(r \frac{\partial p}{\partial r}\right)=\varphi \frac{B_{g}}{\lambda_{g}}\left(\frac{S_{g}^{\prime}}{B_{g}}-\frac{S_{g} B_{g}^{\prime}}{B_{g}^{2}}\right) \frac{\partial p}{\partial t}$

Now equating oil and gas relationships to derive a single equation to describe multiphase flow:

$\varphi \frac{1}{\lambda_{o}}\left(S_{o}^{\prime}-\frac{S_{o} B_{o}^{\prime}}{B_{o}}\right) \frac{\partial p}{\partial t}=\varphi \frac{B_{g}}{\lambda_{o}}\left(\frac{S_{g}^{\prime}}{B_{g}}-\frac{S_{g} B_{g}^{\prime}}{B_{g}^{2}}\right) \frac{\partial p}{\partial t}$

$\frac{\lambda_{g}}{\lambda_{o}}\left(S_{o}^{\prime}-\frac{S_{o} B_{o}^{\prime}}{B_{o}}\right)=\left(S_{g}^{\prime}-\frac{S_{g} B_{g}^{\prime}}{B_{g}}\right)$

$S_{g}+S_{o}=1$

Differentiating Eq. A19a with respect to pressure gives:

$S_{g}^{\prime}+S_{o}^{\prime}=0$

Total mobility in this case is $\lambda_{t}$

$\lambda_{o}+\lambda_{g}=\lambda_{t}$

Substituting Eq. A19a and A20 into A24

$$
\left(S_{o}^{\prime}-\frac{S_{o} B_{o}^{\prime}}{B_{o}}\right)\left\{\left(\frac{\lambda_{t}-\lambda_{o}}{\lambda_{o}}\right)+1\right\}=-\frac{S_{o} B_{o}^{\prime}}{B_{o}}-\frac{S_{g} B_{g}^{\prime}}{B_{g}}
$$

Defining total compressibility, $C_{t}$, and obtaining expressions for oil and gas compressibility in terms of formation volume factor:

$$
C_{t}=S_{o} C_{o}+S_{g} C_{g}
$$

$C_{o}=-\frac{1}{B_{o}} B_{o}^{\prime}$

$C_{g}=-\frac{1}{B_{g}} B_{g}^{\prime}$

Substituting Eq. A22b and A22c into Eq. A22a:

$$
C_{t}=-\frac{S_{o} B_{o}^{\prime}}{B_{o}}-\frac{S_{g} B_{g}^{\prime}}{B_{g}}
$$

Therefore,

$$
\left(S_{o}^{\prime}-\frac{S_{o} B_{o}^{\prime}}{B_{o}}\right)\left(\frac{\lambda_{t}}{\lambda_{o}}\right)=C_{t}
$$

The above equation, Eq. A24, may be substituted into Eq. 1, giving the diffusivity equation to calculate compressibility.

$$
\frac{1}{r} \frac{\partial}{\partial r}\left(r \frac{\partial p}{\partial r}\right)=\varphi \frac{C_{t}}{\lambda_{t}} \frac{\partial p}{\partial t}
$$

